SOฺXว L 


\section{David Bohm, sua estada no Brasil e a Teoria Quântical}

\section{OLIVAL FREIRE JR, MICHEL PATY C ALBERTO LUIZ DA ROCHA BARROS}

$\mathrm{H}$ á quarenta anos o físico David Bohm (1917-1992), nascido norte-americano, em Wilkes-Barre (Pennsylvania), elaborou o trabalho intitulado Uma proposta de interpretafão da teoria qudntica em termos de " Dariápeis escondidas" (2), que marcou a história das interpretaçóes desta teoria. Com esse trabalho buscava uma descriçáo causal e objetiva para os fenômenos quânticos. Quando o trabalho foi publicado ele encontrava-se no Brasil trabalhando na USP, onde permaneceu de outubro de 1951 a
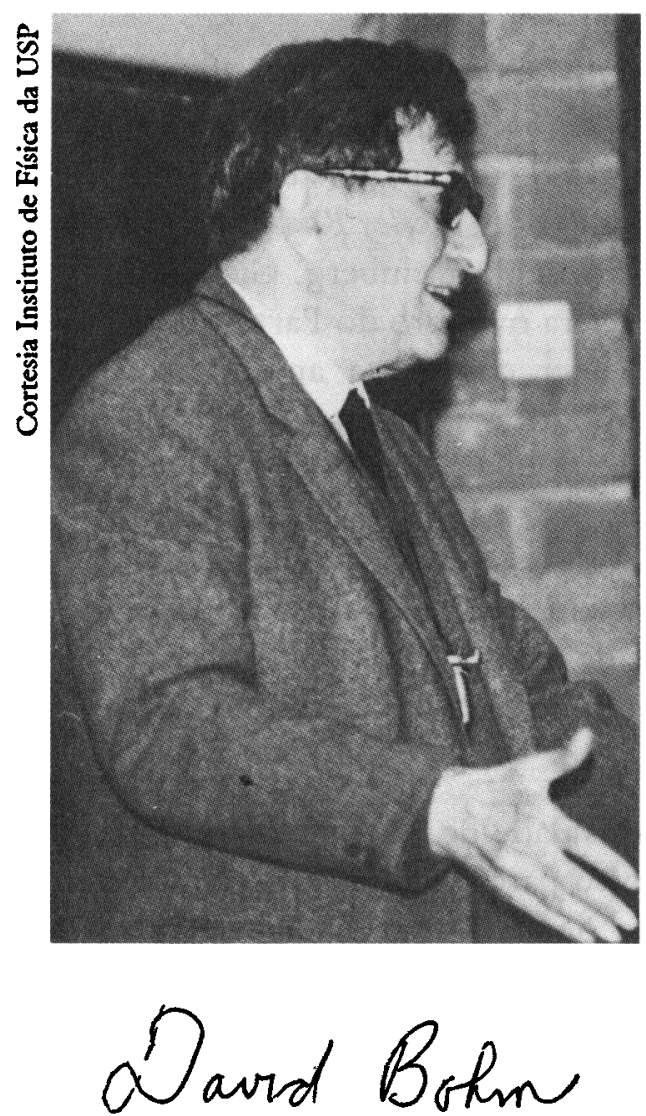
janeiro de 1955.

Atingido pelo McCarthysm pouco antes da elaboraçáo do artigo, Bohm perdeu toda condiçáo de trabalhar nos EUA. Por isto ele veio para o Brasil, no período da recepçáo, pela comunidade científi$\mathrm{ca}$, e do desenvolvimento de seu trabalho.

Para a física brasileira foi também o período da consolidação institucional da pesquisa. Bohm colaborou neste processo, ministrando cursos, proferindo seminários, escrevendo sobre a física, e o ensino, no Brasil e interagindo com físicos brasileiros em função do desenvolvimento de seu programa científico.

A obra científica e filosófica de David Bohm tem sensibilizado 
variados círculos da cultura contemporânea. O seu súbito desaparecimento, em Londres, 27 de outubro de 1992, nos enseja rever a sua estada no Brasil, episódio aliás pouco conhecido mesmo na literatura especializada da história da ciência, e também a proposta de reinterpretaçáo da teoria quântica, incluindo a acolhida da proposta por cientistas como A. Einstein, W. Pauli e L. de Broglie, bem como desenvolvimentos desta proposta e discussóes correlatas, realizadas no Brasil com cientistas como J.P. Vigier, R. Schiller, J. Tiomno, M. Schenberg, W. Schützer, L. Rosenfeld, M.Bunge e R. Feynman.

\section{A vinda de Bohm para o Brasil}

David Bohm obteve doutoramento em física, em 1943, na Universidade da Califórnia, em Berkeley, sob orientação de R. Oppenheimer. A partir de 1946 passou a ensinar na Universidade de Princeton. Publicou uma série de artigos em variados temas da física, em especial sobre oscilaçóes do plasma (3). Escreveu em seguida o livro Quantum Theory, (4), considerado até hoje um clássico no assunto. Aprofundou o interesse pelos fundamentos da teoria quântica elaborando artigos reinterpretando-a. Antes da publicaçăo desses artigos circunstâncias políticas, alheias à sua vontade, forçaram-no a sair dos Estados Unidos.

David Bohm foi uma das vítimas do denominado período do McCarthysm na história dos Estados Unidos (5). Em 1949 a Comissão de Atividades Anti-Americanas do Congresso, dos EUA, dirigiu sua atenção para os físicos que haviam trabalhado no Berkeley Radiation Laboratory, durante a guerra, entre os quais Joseph Weinberg, Giovanni Lomanitz e David Bohm (5). Inquirido se era membro do Partido Comunista ou se conhecia Steve Nelson (líder comunista americano), Bohm invocou, em um gesto de coragem política, a Quinta Emenda da Constituição americana para recusar-se a responder, argumentando que se o fizesse estaria submetendo outras pessoas e a si próprio a perseguições. Foi então acusado de desacato ao Congresso mas ganhou na Justiça o direito de manter tal posição. Contudo, perdeu o cargo na Universidade de Princeton e qualquer chance de continuar trabalhando nos EUA. A saída daquele país foi entáo a condiçáo para dar continuidade à sua atividade cientifica (7).

Para viabilizar a vinda para a Universidade de Sáo Paulo contou com o amigo Albert Einstein, que escreveu para Abraháo de Moraes, entáo Chefe do Departamento de Física da USP, para o Presidente Getúlio Vargas e para o Governador do Estado, Lucas Nogueira Garcez (8), e com o empenho do físico brasileiro Mário Schenberg, Catedrático de Mecânica Racional e Celeste, além de José Leite Lopes e 
Jaime Tiomno, estando os dois últimos em Princeton. Bohm veio acompanhado de seu colaborador Ralph Schiller, atualmente na Syracuse University, nos Estados Unidos.

Na Universidade de São Paulo foi nomeado Professor da Cátedra de Física Teórica e Física Matemática, anteriormente ocupada por Gleb Wataghin, chegando ao Brasil em 10 de outubro de 1951 e permanecendo até janeiro de 1955 . É digno de registro que apesar da conjuntura política brasileira do pós II Guerra ter sido influenciada pela Guerra Fria, especialmente durante o governo Dutra (cassaçáo de mandatos parlamentares, do registro do Partido Comunista e repressão a sindicatos), a sociedade brasileira foi capaz de acolher e manter um cidadáo e cientista perseguido politicamente em seu país de origem.

Bohm chegou ao Brasil em uma fase de institucionalização da pesquisa em física. A primeira instituiçăo brasileira na área, o Departamento de Física da Faculdade de Filosofia, Ciências e Letras da USP, tinha pouco mais de 15 anos de existência. Em 1949 foi criado o Centro Brasileiro de Pesquisas Físicas (CBPF), no Rio de Janeiro, voltado exclusivamente para a pesquisa em física; em 1951, o Conselho Nacional de Pesquisa (CNPq), como órgáo federal de incentivo à pesquisa; e em Săo Paulo, ainda em 1951, foi fundado, o Instituto de Física Teórica (IFT) como instituiçâo independente da USP (9).

Neste período a presença de físicos estrangeiros foi significativa. Além de Bohm, na USP, aqui estiveram R.P Feynman, C.N. Yang, E.P. Wigner e L. Rosenfeld, no CBPF, C.F. von Weizsacker, R. Oehme, H. Joos, M. Taketani e Y. Katayama no IFT. Já se tinha formado, contudo, uma geraçáo de físicos brasileiros que estava em plena atividade de pesquisa: M. Schenberg, M. Damy, O. Sala, em Sáo Paulo e J. Leite Lopes, C. Lattes e J. Tiomno no Rio de Janeiro, entre outros (10). No início da década de 50 a física brasileira adquiriu inclusive uma visibilidade social mais ampla, com diversos jornais nacionais dedicando manchetes e seguidas matérias à descoberta do méson pi - partícula elementar por César Lattes, junto com C.F. Powell e G. Occhialini.

Era portanto ambiente favorável à presença de um físico de projeção, como Bohm, com uma proposta que propiciava controvérsia na comunidade científica internacional. Ele declarou, em 1983: "Quando fui para o Brasil, estava trabalhando numa nova interpretaçăo da teoria dos Quanta, que encerrei agora. Tendo terminado minha pesquisa sobre plasma, estava pensando em seguir mais além, pois estava muito interessado na questão filosófica. Acho que minha ida para o Brasil me deu oportunidade de prosseguir essa discussão, primeiro com Tiomno e 
Schiller, depois com Walter Schützer e, também, com Mário Schenberg - tudo isso me interessou muito, no sentido de ajudar a dar prosseguimento a meu trabalho" (11).

David Bohm ministrou, em português, o curso de Física Teórica durante o ano de 1953 e o de Mecânica Quântica em 1954. As notas do primeiro curso foram objeto de uma publicaçăo interna (12) com o título Curso de física teórica. Entre os alunos estavam Newton Bernardes, Moyses Nussenzveig, Ernst W. Hamburger, Amélia Império, Gerhard Bund e Ewa Cybulska. Desenvolveu atividades multilaterais de ensino, pesquisa (que analisaremos neste artigo), e até administrativas. Organizou seminários regulares, que contaram com a presença de físicos do IFT e do ITA, proferiu vários seminários nos Departamentos de Matemática e Química, denominados $O$ conceito de causalidade em mecanica quantica e $A$ mecanica qudntica na Quimica, respectivamente (13).

Preocupado com a formação da física brasileira elaborou análise comparativa sobre a física e o ensino, no Brasil e nos EUA (14). Observou, criticamente, tendências nos estudantes brasileiros de desprezo ao trabalho manual, concentração em assuntos matemáticos avançados $\mathrm{e}$ crença de que a física desenvolve-se por atos de genialidade.

Manifestou também preocupaçáo com o descaso do governo brasileiro para com a educação superior. Esta preocupação, transmitida a Einstein, motivou a seguinte observação sobre a situação brasileira: "O que mais me espanta é o governo brasileiro náo fazer nenhuma tentativa séria para tornar os altos estudos mais atraentes. Porque isso é uma necessidade absoluta para o desenvolvimento técnico do país. Compare, por exemplo, como o Japão agiu no século XIX" (15)

Embora sua estada tenha sido um período de intensa atividade científica e didática, não foi um período de tranqüilidade pessoal. Bohm nutria o desejo de que modificaçóes na situação política permitissem o retorno ao seu país. A carta escrita para Einstein, em fevereiro de 1954, testemunha as insatisfaçóes. A principal delas é com a instabilidade política de sua situação no Brasil. Ele diz: "... Já circulam rumores de que sou comunista...", e que "os Estados Unidos poderiam também solicitar ao governo brasileiro a minha extradiçăo. Ninguém aqui pode prever qual seria a reação do governo brasileiro se recebesse essa solicitação ...". Tais dificuldades são agravadas "... porque enfrento agora uma espécie de impasse no meu trabalho, e preciso relaxar da tensão e do desalento resultantes" (16). Este desabafo revela também a aguda consciência que Bohm tinha das dificuldades, que examinaremos mais adiante, associadas ao desenvolvimento de seu trabalho. 
A perspicácia e a atualidade, 40 anos depois, das observaçóes de Bohm sobre a realidade brasileira chegaram a despertar a atenção da mídia, quando de sua recente divulgaçăo (17). Mas esta carta é notável também pelo pessimismo quanto às interaçóes profissionais e sociais no Brasil. Este depoimento não é consistente com as discussóes e trabalhos aqui realizados nem com seus depoimentos ulteriores sobre a estada no Brasil. Destoa também dos testemunhos de pessoas que desfrutaram do seu convívio neste período. A explicação para o tom da carta deve ser buscada, a nosso ver, no agravamento da instabilidade da sua situaçáo política. No ano anterior Julius e Ethel Rosenberg foram executados na cadeira elétrica, nos Estados Unidos, nos desdobramentos dos acontecimentos políticos que vitimaram Bohm (18). O final de $1953 \mathrm{e} \mathrm{o}$ ano de 1954 foram também os meses do auge da histeria do McCarthysm (19). É possível portanto que ele tenha agravado a descriçáo das dificuldades aqui vivenciadas visando convencer Einstein a apoiar a ida para Israel, onde acreditava estar mais seguro. A plausibilidade deste argumento fica reforçada se observarmos que neste período Einstein buscava convencer Bohm a permanecer no Brasil e obter cidadania brasileira, ao tempo que desaconselhava a ida para Israel (20).

O contrato com a USP foi renovado a partir de setembro de 1954 por mais três anos, em decreto do Governador Lucas Nogueira Garcez. Mas Bohm já havia decidido ir para Israel, tendo obtido através de $\mathbf{N}$. Rosen um posto na Technion em Haifa. Para isto contou mais uma vez com a ajuda de Einstein que, apesar das reservas iniciais, escreveu para Rosen recomendando-o (21). Quando viajou, em janeiro de 1955, o contrato foi suspenso por um ano após o qual foi rescindido (22). De Israel, onde permaneceu até 1961, foi para a Inglaterra ensinando no Birkbeck College da Universidade de Londres, da qual foi Professor Emérito.

O Professor David Bohm não mais retornou ao Brasil. Mas não perdia de vista a história deste país e manteve contatos estreitos com amigos e colegas brasileiros. Assim foi várias vezes a Estrasburgo, nos anos setenta, a convite de J. Leite Lopes, que ali estava trabalhando depois de ter sido cassado pela ditadura militar do seu posto de professor no Brasil, e de um dos autores (Michel Paty). Em 1983, por ocasião das comemoraçóes dos 70 anos de Mario Schenberg, concedeu extenso depoimento a um dos autores (23). Em janeiro de 1992, perguntado sobre suas lembranças do Brasil, expressou a sua preocupaçáo com os graves problemas sociais do povo brasileiro, em especial com a situaçáo dos meninos de rua (24). 


\section{A reinterpretação da teoria quântica proposta por Bohm}

O interesse de David Bohm pelos fundamentos da teoria quântica náo esgotou-se na redaçáo do seu livro Quantum Theory. Concluído o texto ele enviou-o a W. Pauli, N. Bohr e A. Einstein (25). Pauli manifestou-se elogiando o conteúdo, mas Bohr năo respondeu. Einstein, que trabalhava em Princeton, convidou-o para discussóes quando expôs sua própria apreciação a respeito desta teoria (26). Estas discussões contribuíram para motivar Bohm a buscar uma nova abordagem para estes problemas. Motivado também pelo conhecimento das críticas de físicos soviéticos, como Blokhintsev e Terletski, à interpretação usual da teoria quântica, ele empreendeu a elaboraçáo do trabalho com o qual marcou de forma duradoura sua participação na história da teoria quântica e de sua interpretação (27).

O trabalho publicado em 1952 consiste na construçáo de um modelo físico capaz de reproduzir todos os resultados que podem ser obtidos com a teoria quântica, na sua interpretaçáo usual, mas apoiado em um "quadro conceitual mais amplo" que, com o auxílio de parâmetros adicionais (escondidos), "permite uma descriçáo contínua, detalhada e causal de todos os processos", mesmo no nível quântico. Obtém-se com isto uma recuperaçăo do determinismo próprio à física clássica (28).

Tratava-se de uma reinterpretação porque a teoria quântica, na interpretação usual, atribui à funçáo que descreve sistemas quânticos como átomos e moléculas um significado essencialmente probabilístico. Com esta função $\Psi$ (psi), que é solução da equação formulada por Schrödinger, se obtém, através do quadrado de seu módulo, as probabilidades de obtençáo dos valores das grandezas físicas envolvidas. Denominada também de interpretaf̧aio de Copenbagen (29), ela afirmou-se na comunidade científica como a interpretação da teoria quântica, em que pese a discordância de físicos eminentes como Schrödinger, Einstein e de Broglie. Este último tentou, entre 1926 e 1927, uma descrição causal da teoria quântica, introduzindo variáveis adicionais às já usadas (teorias da dupla soluçáo e da onda-piloto), mas desistiu deste programa.

Bohm, contudo, não tinha conhecimento prévio destes trabalhos alternativos mais antigos. É devido a esta precedência, de trabalhos como os de L. de Broglie, que o historiador da ciência Max Jammer denominou a discussão desencadeada, pelo trabalho de Bohm, na comunidade científica no início da década de 50 como $O$ renascimento, por Bobm, das pariápeis escondidas. 
Após a elaboraçáo do artigo, e antes da publicaçăo, Bohm tomou conhecimento dos trabalhos prévios e das críticas a eles feitas na época, que se aplicavam também ao seu. Registrou entáo a precedência e desenvolveu ainda mais sua proposta buscando superar as críticas. $O$ desenvolvimento realizado foi basicamente a aplicaçáo do próprio modelo ao processo de medida dos sistemas quânticos e foi publicado como a segunda parte do mesmo artigo, conjuntamente com a primeira. Com este desenvolvimento a próposta de Bohm evitava a crítica - impossibilidade de descrever experiências de colisóes inelásticas - feita por Pauli (30) à proposta de L. de Broglie, em 1927.

O modelo construído por Bohm trata um sistema quântico, um elétron por exemplo, como uma partícula com posiçáo e momento bem definidos, em todos instantes, e submetida a um campo físico real análogo, mas não idêntico, ao campo eletromagnético, e que estaria na origem de suas propriedades quânticas. Reescrevendo a funçăo, que é solução da equação de Schrödinger, ele busca analogias com a física clássica, especialmente com o formalismo hamiltoniano da mecânica. Um obstáculo a esta analogia é que a energia mecânica total, representada pelo Hamiltoniano, comparece nas equaçóes derivadas por Bohm com um terceiro termo (além das energias cinética e potencial) que náo tem análogo clássico. Bohm propóe entáo interpretar literalmente este termo como um potencial náo clássico, que ele denomina de potencial qudnti$\operatorname{co}(31)$.

Neste modelo a mecânica newtoniana clássica não perde a validade no domínio quântico, e Bohm a expressa escrevendo a segunda lei de Newton para uma partícula quântica. Com a equaçáo de movimento dada pelas leis de Newton e mais as condiçóes iniciais tem-se entáo recuperado o conceito de trajetória no espaço-tempo que perdeu seu sentido exato na interpretaçáo usual da teoria quântica. Como se sabe, a teoria quântica não admite uma definiçăo, e mediçáo, simultânea das variáveis momento e posiçáo. $\mathrm{Na}$ interpretaçáo usual da teoria quântica elas estáo condicionadas pelas relafóes de indeterminafáo de Heisenberg. A descriçáo no espaço-tempo (trajetórias bem-definidas) e as leis de conservação do momento e da energia (que não dependem das trajetórias) são abordagens complementares na visăo de Niels Bohr, devido à finitude do quantum de açáo expresso pela constante de Planck. No modelo de David Bohm, as variáveis momento e posiçáo de uma partícula, bem-definidas, sáo denominadas suas variáveis suplementares, ou escondidas, com relação à teoria quântica. Elas têm existência simultânea, porém náo aparecem explicitamente no processo a nảo ser na forma do potencial quântico. 
Para a consistência da interpretação Bohm adotou premissas (32) adicionais ao seu próprio modelo que, năo sendo inerentes ao quadro conceitual da interpretaçáo proposta, poderiam ser relaxadas, por exemplo, para regióes da ordem de $10^{-13} \mathrm{~cm}$ - dimensóes do núcleo atômico - levando então a previsóes distintas daquelas da interpretaçáo usual. Ele chega a assinalar possíveis modificaçôes no seu modelo, mas não as desenvolve.

Conseguindo reproduzir, com seu modelo, alguns dos principais resultados da teoria quântica náo-relativística, Bohm obteve êxito em seu propósito básico, o de demonstrar a possibilidade de uma interpretação causal para os fenômenos quânticos.

Cabe notar que a proposta de Bohm, extensiva ao processo da medida, incorpora também variáveis escondidas nos aparelhos de medida; estas sáo incluídas na construçáo do Hamiltoniano da interaçáo aparelho-sistema. A teoria proposta implica a mesma propriedade, contida na interpretaçáo usual, de não-localidade para sistemas separados espacialmente que interagiram no passado, propriedade que tinha sido apontada e criticada por Einstein no seu argumento EPR. A náo-localidade, no modelo de Bohm, é decorrência de considerar os resultados das medidas de grandezas físicas como resultantes da interação dos sistemas com os aparelhos de medida. É importante notar que o modelo de Bohm é determinístico e náo-local (33). As variáveis escondidas evitam, pelo seu caráter náo-local, a prova de impossibilidade de Von Neumann, de 1932, como John Bell (34) observou em 1966.

\section{A recepção da proposta de Bohm na comunidade científica}

O trabalho de Bohm desencadeou forte repercussão na comunidade científica. Pelo menos os seguintes cientistas o analisaram: A. Einstein, L. de Broglie, W. Pauli, O. Halpern, S.T. Epstein, T. Takabayasi, J.B. Keller, J.P. Vigier, E. Schatzman, H. Freidstadt, L. Rosenfeld, J.L. Destouches (35).

Prevaleceram atitudes críticas embora tenha existido adesóes, em geral no terreno epistemológico. Mas as críticas não tiveram o caráter de uma refutaçáo direta no terreno estrito da física, ou seja, não foram apontadas discrepâncias entre a interpretaçáo de Bohm e resultados experimentais. As críticas dirigiram-se à consistência física do modelo ou à sua moldura epistemológica. Bohm não aceitou passivamente as críticas. Polemizou com quase todas (36). Mas o fez em geral apresentando novos argumentos e mesmo desenvolvendo o seu programa. Estas 


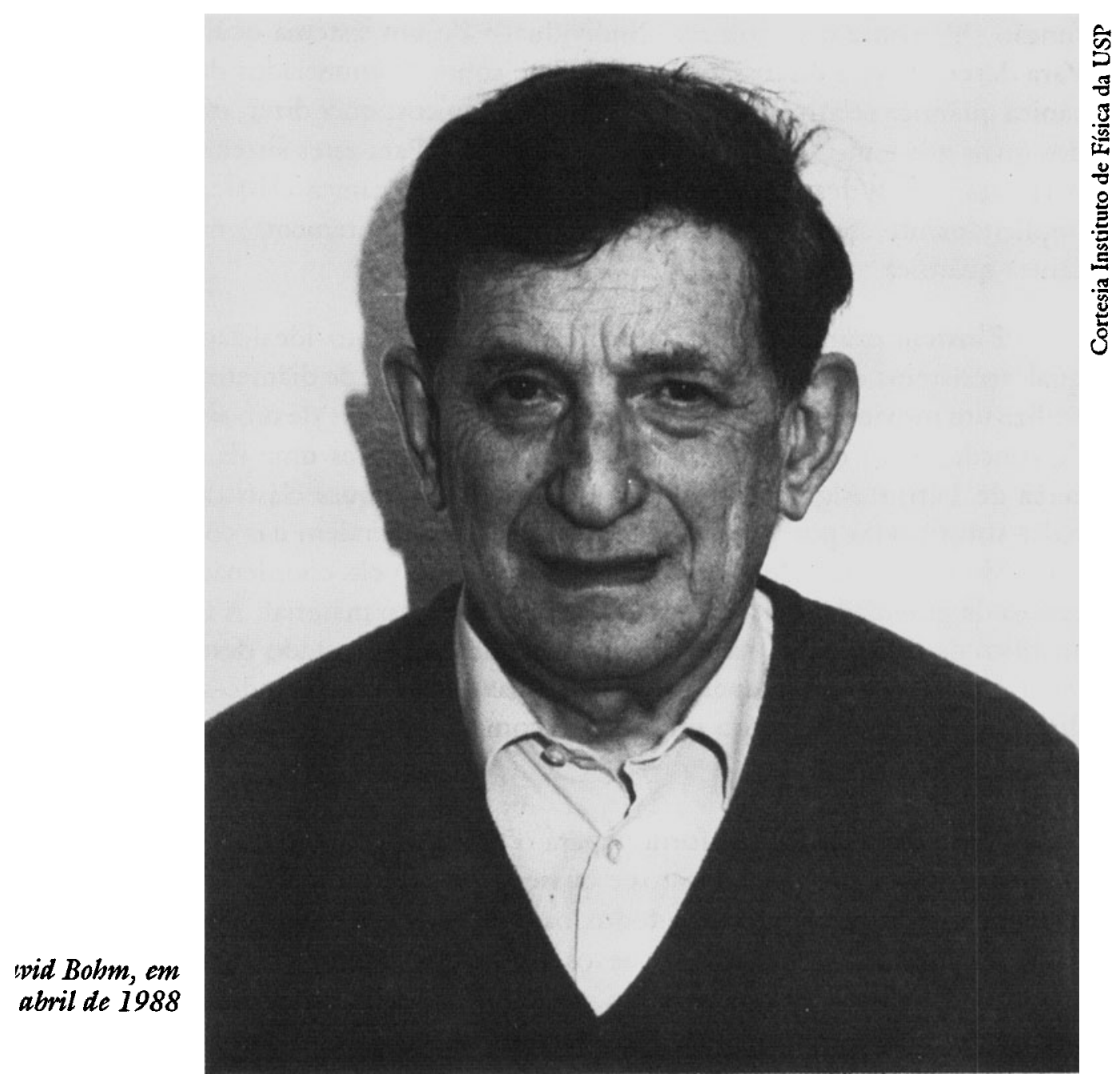

respostas e estes desenvolvimentos foram elaborados quando da estada na USP (37). Aliás quando o artigo inicial - $A$ suggested interpretation of the Quantum Theory in terms of "hidden" variables foi publicado, $O$ endereço institucional de Bohm já era a Universidade de Sáo Paulo. Examinemos algumas das reaçóes da recepção:

\section{$O$ debate com Einstein}

A recepção crítica de Einstein, provavelmente não esperada por Bohm, é muito esclarecedora da natureza das posiçóes do primeiro sobre a teoria quântica. Há no período uma intensa correspondência entre Einstein e Bohm (38). As divergências tornam-se públicas, em 1953, por ocasião da edição de livro em homenagem a M. Born.

Einstein (39) se propóe a discutir a questão: "... que diz a 
função $\Psi$ sobre o estado real (individual)" de um sistema quântico? Para desenvolver a discussão ele "... reflete sobre os enunciados da mecânica quântica relativos aos sistemas macroscópicos; quer dizer, objetos dos quais nós temos evidências sensíveis diretas": Para estes sistemas ele pergunta: "... a descrição ' real' fornecida pela mecânica clássica está implicitamente contida (de forma aproximada, evidentemente) na mecânica quântica?"

Einstein examina concretamente um experimento idealizado no qual "o sistema é constituído por uma esfera de $1 \mathrm{~mm}$ de diâmetro, que realiza um movimento de vai-e-vem (ao longo do eixo ' $\mathrm{x}$ ' de um sistema de coordenadas) entre duas paredes paralelas (distantes uma da outra cerca de $1 \mathrm{~m}$ )." Algumas idealizaçóes sáo feitas: choques elásticos, paredes substituídas por pofos de potencial que só dependem das coordenadas de posiçáo e esfera descrita exclusivamente pela coordenada do centro de gravidade, ou seja, tratada como um ponto material. A forma analítica da função que, na teoria quântica, descreve o estado deste sistema é dada por uma superposição de duas ondas propagando-se em direçóes opostas. Ele coteja esta função com as interpretaçóes disponíveis.

A interpretaçáo usual fornece para o momento da partícula "dois valores nítidos e precisos, opostos e quase iguais, coincidindo aliás com os valores clássicos, e afetados todos os dois com a mesma probabilidade". Einstein conclui então que os resultados seriam os mesmos, aproximadamente, obtidos para um conjunto de várias esferas macroscópicas tratadas classicamente. Ele conclui com o seu conhecido diagnóstico sobre a teoria quântica: a interpretação estatística, proposta por M. Born, é "perfeitamente satisfatória" mas incapaz de uma descrição real de um sistema individual, já que em cada caso individual clássico nós teremos sempre um dos dois valores para o momento da esfera.

A sua insatisfaçáo com a proposta de Bohm é muito simples de ser relatada. É que nesta interpretação a velocidade da partícula (40) será sempre nula. A interpretaçáo proposta por Bohm é pouco plausível e por isto insatisfatória já que "... o fato que a velocidade seja nula está em contradiçăo com a exigência, bem fundada, segundo a qual para um sistema macroscópico o movimento deve ser aproximadamente idêntico àquele que decorre da mecânica clássica." A conclusão geral extraída por Einstein é bastante forte no contexto da recepção à proposta de Bohm. Conforme Einstein, "das consideraçóes precedentes resulta que a única interpretação da equaçáo de Schrödinger admissível, até o presente, é a interpretaçáo estatística dada por Born." 
A crítica de Einstein, contudo, năo colocou para Bohm uma situaçáo nova. É que ele já tinha tratado, no artigo de 1952, de uma situaçáo análoga, isto é: "o problema de uma partícula livre contida entre duas paredes impenetráveis e perfeitamente refletoras" (41). Ele tratou deste problema motivado pelo trabalho de N. Rosen (42) que havia examinado o mesmo modelo, desenvolvido ulteriormente por Bohm, e descartou-o ao constatar que para ondas estacionárias o modelo descrevia partículas sempre em repouso ou era incapaz de descrever os fenômenos de interferência. $\mathrm{Na}$ visáo de Rosen isto conflitava com a idéia de um elétron confinado, por exemplo no átomo de Hidrogênio, para o qual o tratamento quântico adequado supōe variáveis, como momento angular, contraditórias com a imagem de um elétron em repouso.

Na sua resposta a Einstein, Bohm afirma (43), com naturalidade, que efetivamente no seu modelo para a interpretação causal a partícula estará em repouso, mas que a aplicaçáo da proposta ao próprio processo de medida destruiria esta funçăo $\Psi$ reduzindo o pacote de ondas a valores de momentos $(+\mathrm{p}$ e $-\mathrm{p})$ igualmente prováveis, levando a "resultados experimentais equivalentes aos previstos pela interpretaçáo usual."

A resposta não podia satisfazer Einstein, pois se referia a uma submissáo do significado do fenômeno às condiçōes da observação. Com efeito para Bohm obter resultados compatíveis com os da teoria quântica era necessário aplicar o modelo das variáveis escondidas ao próprio processo de medida, condicionando por isto a descriçáo dos fenômenos quânticos à interaçáo com os aparelhos de medida. Característica epistemológica comum à proposta de Bohm e à interpretaçáo usual (44), e inaceitável para Einstein.

\section{A crítica de Pauli e outras criticas à consisténcia física do modelo de Bobm}

Uma das críticas mais importantes feita por Pauli (45), nesta fase dos debates sobre os fundamentos da teoria, foi que a validade geral da equivalência feita por Bohm entre o campo associado ao potencial quantico do modelo proposto e a distribuiçăo de probabilidade associada à função de onda da teoria quântica não se sustentava, pois a segunda tinha seu significado delimitado pelo seu próprio quadro teórico. Crítica semelhante foi sustentada também por J.B. Keller (46).

Outros físicos, como O. Halpern e T. Takabayasi (47) concentraram as críticas no fato que a proposta de Bohm reproduzia os resultados da teoria quântica não-relativística, mas não fazia o mesmo para 
fenômenos que dependessem da variável spin, os quais podem ser tratados pela formulação relativística da teoria quântica elaborada por Dirac. Estes autores sustentaram não ser possível desenvolver o modelo de Bohm de forma a concordar com a mecânica quântica relativística. Esta crítica, no contexto da física do início dos anos 50, adquiria bastante força pois a teoria quântica relativística acabava de receber significativo desenvolvimento nos trabalhos de R. Feynman, S. Tomonaga e J. Schwinger.

\section{Adesōes e críticas epistemológicas}

A perspectiva epistemológica de recuperaçáo de uma descrição física determinista e objetiva, no sentido clássico, recebeu adesóes de físicos como H. Freidstadt, nos EUA, e E. Schatzman, na França (48). Mas exatamente esta perspectiva foi objeto de críticas essencialmente epistemológicas por L. Rosenfeld (49) que defendeu as aquisiçóes conceituais e epistemológicas da interpretação usual da teoria quântica. É notável que os três autores pretenderam apoiar-se no mesmo terreno filosófico - materialismo dialético - mas defendendo distintas interpretaçōes físicas para esta teoria. Já T. Takabaysi (50), embora explorando modelos físicos semelhantes ao construído por Bohm considerou "um passo atrás", e "metafísica", a busca de uma descriçáo causal clássica por não levar a previsões distintas das existentes nas teorias já estabelecidas.

A atitude de Louis de Broglie, bem como a de J.P. Vigier, não é passível de um enquadramento único pois combinou uma adesão ao programa epistemológico de recuperaçăo da descriçăo causal clássica com criticas quanto à simplicidade do modelo físico (51). O retorno de Louis de Broglie às suas posiçóes de 1926-1927 foi motivado pela situaçáo insólita de Bohm ter retomado e desenvolvido o modelo original, de L. de Broglie, a ponto de livrá-lo das críticas sofridas à época, mas também pelas discussóes realizadas com J.P. Vigier, entáo seu assistente.

\section{Desenvolvimentos no trabalho de Bohm em sua estada no Brasil}

A sensibilidade de Bohm à crítica de W. Pauli e J.B. Keller ficou evidente quando dedicou dois trabalhos à demonstraçáo de que a grandeza representando a densidade de probabilidade de seu modelo, que é arbitrária, pode ser igualada aos valores da densidade de probabilidade própria da teoria quântica, justificando assim a associaçáo entre as duas grandezas. Aliás entre os dois trabalhos existe um percurso, e uma mudança no modelo adotado por Bohm. No primeiro trabalho, apresen- 
tado em janeiro de 1953, ele anuncia um artigo a ser publicado nos Anais da Academia Brasileira de Ciencias, no qual será apresentada uma prova geral da possibilidade desta associaçáo, pois neste primeiro trabalho a prova está baseada em um exemplo ilustrativo simples.

O trabalho anunciado por Bohm, contudo, nāo foi publicado. Já no segundo trabalho (53), em conjunto com J.P. Vigier, apresentado em junho de 1954, um ano e meio depois, aparece a explicaçáo: "No trabalho citado acima (54), todavia, certas dificuldades matemáticas tornam muito difícil uma generalizaçăo dos resultados para um sistema arbitrário ... No presente artigo evitaremos estas dificuldades beneficiando-nos do fato que a interpretação causal da teoria quântica permite um número ilimitado de novos modelos físicos, de tipos náo consistentes com a interpretaçáo usual e que levam a esta táo somente como uma aproximação".

O modelo trabalhado no artigo não é mais aquele da partícula, com trajetória bem definida, sob influência de um campo físico derivado do potencial quantico, mas sim um modelo hidrodinâmico, proposto originalmente por Madelung em 1926, no qual a densidade do fluido é associada, por analogia, à densidade de probabilidade própria da teoria quântica. Para obter uma descriçáo causal da localizaçáo de uma partícula os autores acrescentaram a este modelo uma inomogeneidade altamente localizada movendo-se com a velocidade do fluxo. Admitiu-se também a existência de flutuaçóes aleatórias nos movimentos deste fluido. Os autores não desenvolveram hipóteses sobre a natureza destas flutuaçóes, elas foram adotadas como premissas, condicionadas a que seus valores médios fossem associados às grandezas próprias da interpretaçăo usual da teoria quântica. Bohm e Vigier denominaram este fluido sujeito a flutuaçóes aleatórias de nível sub-quantico. Como o principal resultado do artigo foi "... responder uma importante objeção à interpretaçáo causal, feita por Pauli e outros", podemos concluir que foram as dificuldades matemáticas implicadas nesta prova que levaram Bohm a abandonar o modelo original e trabalhar com o modelo hidrodinâmico da teoria quântica.

Para a elaboraçáo do artigo, J.P. Vigier, que entâo trabalhava com L. de Broglie no Instituto Henri Poincaré, em Paris, passou um mês em Sáo Paulo. Para esta estada Vigier contou com subsídios do Conselho Nacional de Pesquisas - CNPq - e da Seção de Relaçóes Culturais da França. Este trabalho representou também uma aproximaçăo entre o trabalho cientifico de Bohm e L. de Broglie (55).

\section{$O$ desafio da generalizafá̃o relatipistica}


Generalizar os modelo de variáveis escondidas para o caso relativístico foi outro grande desafio enfrentado por Bohm ainda no Brasil. Mas só após o trabalho conjunto com J.P. Vigier, já no modelo hidrodinâmico, é que o desafio recebeu um tratamento mais desenvolvido, $e$ isto foi feito em dois trabalhos em conjunto com R. Schiller e com o físico brasileiro J. Tiomno (56), então na USP. Nestes trabalhos é obtido o spin do elétron reproduzindo resultados da equaçáo de Pauli. Mas a equação obtida ainda não é relativística. Bohm e Schiller afirmam: "Certamente nós não acreditamos que um modelo baseado sobre uma explicação da equação de Pauli será realmente adequado aos propósitos descritos no parágrafo anterior porque ele não é relativístico. Um modelo baseado sobre uma explicação da equação de Dirac (e melhor ainda com segunda quantizaçáo) deveria, contudo, dar um tratamento muito mais preciso do que seria possível com o modelo dado neste artigo." As dificuldades associadas à generalização relativística dos modelos construídos por Bohm náo foram superadas, fato reconhecido pelo próprio Bohm em escritos posteriores (57).

Tiomno trabalhou com Bohm motivado pela busca das consequiências - matemáticas e físicas - do modelo adotado, mas sem compartilhar o programa epistemológico da recuperaçáo de uma descriçáo causal (58). Por esta razáo, e pelas mudanças, sua para o Rio de Janeiro e de Bohm para Israel, este trabalho náo teve desdobramentos na produçáo cientifica ulterior de Jaime Tiomno.

Bohm realizou, ao longo dos anos 60 , importante flexáo no seu programa cientifico e epistemológico. Abandonou os modelos concretos de 1952-54, justificando que "todas as noções (variáveis escondidas) sáo bastantes consistentes logicamente. Mas deve ser admitido que elas são difíceis de entender de um ponto de vista físico ... elas deveriam ser vistas, como o próprio potencial quântico, como representaçōes esquemáticas ou preliminares de certas características de algumas idéias físicas mais plausíveis a serem obtidas ulteriormente" (59).

A percepçáo do potencial quantico como representaçáo esquemática de idéias físicas mais plausíveis levou-o a dedicar-se, dos anos $70 \mathrm{em}$ diante, ao projeto de matematizar uma intuiçáo derivada da proposta de 1952. Ele viu no potencial quantico que dependia das coordenadas de todo o sistema uma indicaçáo mais geral: a de uma teoria física na qual cada parte dependesse de todo o Universo, denominando esta intuiçáo de implicate order (60). O desenvolvimento destas novas idéias físicas diferiu também dos seus trabalhos do inicio dos anos 50 . Ao invés de buscar modelos físicos para reproduzir as previsóes da teoria quântica, Bohm desenvolveu seu programa buscando evidenciar as propriedades 
matemáticas (algébricas) mais gerais contidas no formalismo da teorias quântica e relativística.

Mas a flexão não foi restrita à abordagem física. A ênfase na recuperação de uma descrição causal dos fenômenos quânticos foi atenuada, subordinando-se ao propósito de revelar o que chamou de nova ordem em física, entendendo por isto o quadro conceitual mais geral subjacente à relatividade e aos quanta. Uma evidencia desta modificaçáo epistemológica nós encontramos no artigo inaugural do programa da implicate order, acima referido. Bohm recorre ao sentido latino original da palavra ratio para mostrar que ela tem um significado mais amplo que a palavra reason, afirmando em seguida: "Lei racional náo está restrita a uma expressão de causalidade. Evidentemente que razáo, no sentido aqui atribuído, vai bem além de causalidade, a qual é um caso especial de razão", e "deste modo, uma lei causal fornece um certo tipo limitado de razão. Contudo, de modo mais geral, uma explicação racional toma a forma: 'se objetos estão relacionados em um certo conceito, ou idéia, então eles estão relacionados de fato' " (61). O programa da implicate order é hoje um programa em desenvolvimento, despertando atençôes em círculos culturais mais amplos que a comunidade dos físicos (62).

Além de suas próprias propostas de reinterpretaçáo da teoria quântica, David Bohm deu outras importantes contribuiçóes ao esclarecimento dos fundamentos desta teoria. Em 1959, junto com Y. Aharonov mostrou que a teoria quântica implicava que um dos potenciais eletrodinâmicos - o potencial vetor - tenha significado físico, embora na física clássica este potencial tenha significado apenas matemático; efeito que hoje é conhecido como efeito Bobm-Abaronop (63). Ainda com Aharonov e no final da década de 50, mostrou que experimentos já realizados com fótons criados na aniquilação elétron-pósitron podiam ser reinterpretados para fins de verificaçáo do experimento EPR, proposto em 1935 por Einstein. E que os resultados destes experimentos confirmavam as previsões da teoria quântica, antecipando-se em certo sentido aos contemporâneos testes experimentais das desigualdades de Bell (64).

Bohm tem o mérito de, com os modelos de variáveis escondidas (ainda que pouco plausíveis, como ele mesmo reconheceu posteriormente), ter contribuído para reavivar a discussão sobre os fundamentos da teoria quântica (65). Discussão esta que guarda atualidade com importantes desenvolvimentos nas últimas décadas. 


\section{Discussões, no Brasil, sobre a teoria quântica}

David Bohm discutiu muito com Mário Schenberg mas não há trabalhos publicados pelos dois. Uma evidência das discussóes nós temos na afirmação de Bohm que passou a "estudar a História da Filosofia, considerando o desenvolvimento do mecanicismo, principalmente, depois de discussóes com Mário Schenberg, sobre uma abordagem dialética da causalidade" (66). Mas as indicações que dispomos mostram uma distância entre os dois com referência à apreciação epistemológica da teoria quântica, ou pelo menos quanto à proposta formulada por Bohm.

Mario Bunge, físico e filósofo argentino, contemporâneo das discussóes entre Bohm e Schenberg, pois veio para o Brasil para trabalhar com Bohm, testemunhou as diferenças afirmando: "Meu segundo encontro com Schenberg foi em 1953 no Instituto de Física, entáo localizado na rua Maria Antonia. Ele tinha retornado da Europa há pouco e eu usava uma bolsa de estudos para passar o semestre trabalhando com David Bohm. Desta vez nosso encontro năo foi tăo feliz quanto o primeiro porque eu tinha me convertido à teoria das variáveis escondidas de Bohm, da qual Schenberg discordava. Quando eu abordei-o com algumas idéias sobre partículas, ele cortou-me subitamente: 'Eu não estou interessado em partículas' . Naquela época eu fiquei chocado com tal aparente conservadorismo. Poucos anos depois eu percebi o quanto ele estava certo" (67).

A análise dos próprios trabalhos de Schenberg sobre fundamentos da teoria quântica publicados no período indica que ele dialogava com o programa proposto por Bohm mas sem uma identificaçáo. Schenberg estava mais interessado em explorar diferenças - formais e empíricas com relaçáo à interpretação usual, decorrentes de generalizaçōes no formalismo da teoria quântica, do que em desenvolver a proposta original de Bohm no sentido de reproduzir os resultados previstos pela interpretação usual. Neste sentido, elaborou uma generalização não-linear da teoria quântica (68), apresentando soluçóes para o formalismo generalizado (69). Tendo aplicado os métodos de segunda quantizaçáo à estatística clássica e à teoria clássica de campos e chegando à conclusão que este método não é essencialmente quântico, estende a sua aplicação à interpretaçáo hidrodinâmica proposta por Madelung em 1926 (70). Mostra entáo que as trajetórias das partículas, do modelo de Bohm, podem ser deduzidas das linhas de fluxo. Schenberg explora diversas possibilidades buscando identificar as propriedades matemáticas, e físicas, subjacentes ao formalismo da teoria quântica, mas sem a preocu- 
paçáo com a recuperação de uma descrif̧áo causal e objetiva, lema epistemológico da produçáo de Bohm.

Podemos contudo falar de uma tardia aproximação entre Bohm e Schenberg sobre os fundamentos da teoria quântica. Vejamos por que "tardia". Numa série de artigos publicados a partir de 1957, Schenberg buscou generalizaçóes das estruturas algébricas subjacentes ao formalismo da teoria quântica (71). Estes trabalhos têm correlaçáo com as tentativas, feitas por Bohm e Basil Hiley, da década de $70 \mathrm{em}$ diante, de matematizar as intuiçóes associadas à implicate order. Perguntado, no início dos anos $\mathbf{8 0}$, sobre a teoria dos spinors (entes matemáticos fundamentais na mecânica quântica relativística) e a sua visão algébrica da realidade física, Bohm respondeu: "Isso também surgiu do meu contato com Mário Schenberg, que deu uma enorme contribuição a esse respeito. Pode-se ter uma visão da Mecânica Quântica Fermiônica e Bosônica através da Álgebra, e Schenberg realizou essa ligaçáo (outras pessoas também fizeram o mesmo, porém mais tarde). Para expressar a implicate order, trabalhamos numa continuação, numa extensão de idéias semelhantes" (72). Observamos, quanto ao alcance destes trabalhos, que Schenberg "dava uma idéia clara da introdução da supersimetria ao nível das álgebras geométricas", conforme apontado por Normando Fernandes (73). Mas o desenvolvimento deste programa científico sofreu injunçóes derivadas do golpe militar de abril de 1964: "se os acontecimentos políticos da época fossem outros, se Schenberg náo tivesse sofrido perseguiçōes políticas e ameaças de prisáo, provavelmente o capítulo da supersimetria teria os físicos brasileiros em destaque" (74).

O reconhecimento mais expressivo da tardia aproximaçáo está na introduçáo de um dos primeiros artigos de Bohm sobre o tema. Registrando as diversas interpretaçóes existentes para o significado dos spinors, Bohm identifica a singularidade do caminho trilhado por Schenberg, que estabeleceu uma relaçāo destes objetos com o espaço de fase, para afirmar significativamente "Neste artigo nós começaremos combinando a Álgebra de Clifford com a interpretaçáo de Schenberg do espaço de fase, mostrando a inter-relaçăo dos dois e desenvolvendo, de forma sistemática, o conjunto da teoria" (75). F.A.M. Frescura e B. Hiley, que trabalharam com Bohm neste programa também identificaram a contribuiçáo do físico brasileiro afirmando: "Os aspectos geométricos destas álgebras já tinham sido discutidos por Schenberg, embora a motivaçáo do seu trabalho fosse bastante distinta" (76).

Durante a estada de Bohm no Brasil, aqui estiveram R.P. Feynman e L. Rosenfeld, ambos como professores visitantes no Centro Brasileiro de Pesquisas Físicas - CBPF - no Rio de Janeiro. Discus- 
sões entre Bohm e Feynman ficaram registradas quando o primeiro declarou, ao final de um dos artigos da época (77), que "deseja agradecer ao Professor R.P. Feynman por várias discussóes interessantes $\mathrm{e}$ estimulantes."

Indicaçōes de discussōes, no Brasil, entre Bohm e Rosenfeld são mais escassas. Rosenfeld trabalhava neste período exatamente sobre questōes epistemológicas associadas à teoria quântica. Publicou nos Anais da Academia Brasileira de Ciencia o artigo Causalité statistique et ordre en physique et en biologie (78), considerado pelo próprio autor como importante "... para esclarecer seus pensamentos sobre os problemas biológicos" (79). Publicou também, em português, artigo de divulgaçáo intitulado $A$ filosofia da física atómica, no qual faz defesa da interpretação usual e do pensamento de Niels Bohr (80). Rosenfeld esteve na USP realizando seminário que contou com a participação de Bohm. A ausência de referências mútuas, ou de colaboraçâo, entre Bohm e Rosenfeld, apesar dos dois estarem trabalhando sobre o mesmo tema, no mesmo país e na mesma época, explica-se pela distância, já referida, entre suas respectivas posiçōes sobre a interpretação da teoria quântica.

O diálogo com Feynman provavelmente foi facilitado pela posição cautelosa que ele adotou, à época, quanto aos desdobramentos imediatos da física. Em artigo publicado, nos Anais da Academia Brasileira de Ciencias, Feynman examina "uma lista dos problemas fundamentais em física teórica", cita as diversas tentativas de soluçáo em curso referindo-se à " teoria do campo não-local, reinterpretação da mecanica quantica (grifos nossos), ... etc" para, de forma significativa, afirmar que, "como uma reflexão atual mostra, não existe em absoluto bases, que não os preconceitos autoritários, sobre as quais seu valor potencial possa ser julgado (a menos que elas já estejam em discordância com experimentos conhecidos) até que uma delas chegue a obter êxitos" (81).

As discussōes entre Bohm e Feynman tiveram o testemunho de Leite Lopes, que refere-se às discussóes realizadas durante a Reuniáo Anual da Sociedade Brasileira para o Progresso da Ciência (SBPC) em Belo Horizonte, no ano de 1952, registrando o contraste com físicos que à época hostilizaram Bohm reduzindo o seu modelo a uma tentativa ideológica de reinterpretação da mecânica quântica. Cartas de Feynman para Leite Lopes (fevereiro de 1954 e maio de 1955) revelam também que o primeiro cogitava de "escrever alguns artigos sobre a interpretaçáo quântica de Bohm, para publicá-los no Brasill, planos estes que não se concretizaram (82). 
Bohm participou do Simpósio Internacional sobre Novas Técnicas de Pesquisa em Física realizado em Sáo Paulo e no Rio de Janeiro, entre 15 e 29 de julho de 1952. Após a apresentaçáo do modelo das variáveis escondidas vários físicos debateram sua proposta. H.L. Anderson, D.W. Kerst, M. Moshinsky e Leite Lopes perguntaram sobre testes que pudessem diferenciar a interpretaçáo de Bohm dos resultados obtidos com a interpretação usual. Ele argumentou que sua própria proposta, bem como os meios técnicos disponíveis para a experimentação, precisariam ser desenvolvidos para evidenciar tais diferenças. Anderson quis saber sobre a indiscernibilidade das partículas (característica das estatísticas quânticas) e Bohm respondeu que esta propriedade não era submetida diretamente a testes experimentais e que os resultados que decorressem da indiscernibilidade poderiam ser obtidos pelo modelo das variáveis escondidas; não satisfazendo, contudo, a Anderson. A. Medina perguntou se Bohm poderia introduzir o spin em sua teoria - aliás a mesma questão foi levantada, no mesmo ano, por Halpern e Takabayasi. Bohm responde que sua teoria não predizia o spin mas poderia descrevê-lo através de uma analogia com a equação de Pauli.

A discussáo mais acirrada foi com I.I. Rabi. Ele perguntou o que Bohm queria exatamente dizer por uma particula. E sustentou que não havia na proposta das variáveis escondidas outras idéias que não as da teoria quântica, querendo dizer com isto que aquela proposta náo abria uma perspectiva própria para o desenvolvimento da física. Bohm sustentou que não havia, à época, razóes empíricas para decidir sobre a superioridade de uma das interpretaçóes da teoria quântica, e que as críticas feitas por Rabi eram análogas às que os anti-atomistas do século XIX fizeram aos defensores da hipótese atomista (83).

Bohm publicou com Walter Schützer, físico brasileiro, da USP, uma análise de problemas estatísticos em física e sua relação com a teoria das probabilidades (84). O objetivo do artigo é mostrar que em certos problemas estatísticos da física é vantajoso, e mesmo necessário, ir além do quadro conceitual presente na teoria das probabilidades.

Bohm e Schützer consideraram como adequada aos problemas estatísticos $\mathrm{d}$ física a chamada interpretaf̧ão objetiva mas identificaram insuficiências na versão desta interpretação denominada de frequéncia relativa, em especial criticaram a identificaçáo entre probabilidade $\mathrm{e}$ frequência relativa. Exemplificando com o lançamento de um dado eles sustentaram que "... a probabilidade é propriedade objetiva do dado mais o processo pelo qual ele é lançado e que manifesta-se aproximadamente como uma frequência relativa em uma longa série de lançamentos." Trata-se de uma antecipação da idéia de que a probabilidade 
de um evento singular é uma propriedade tanto do objeto quanto das condiçóes experimentais a que o objeto será submetido, desenvolvida por K. Popper e denominada por este de interpretajāo da propensáio.

Para Popper "[ as probabilidades] caracterizam a disposifáo, ou a propensán, do arranjo experimental provocar certas freqüências características quando o experimento é repetido muitas vezes". Assinalando a diferença com a interpretafão das freqüências (puramente estatística), ele afirmou que a interpretaçáo da propensáo "considera a probabilidade como uma propriedade mais característica do dispositivo experimental do que da sequiência" de eventos. É digno de nota que Bohm tenha valorizado esta interpretaçáo quando ela foi apresentada à comunidade

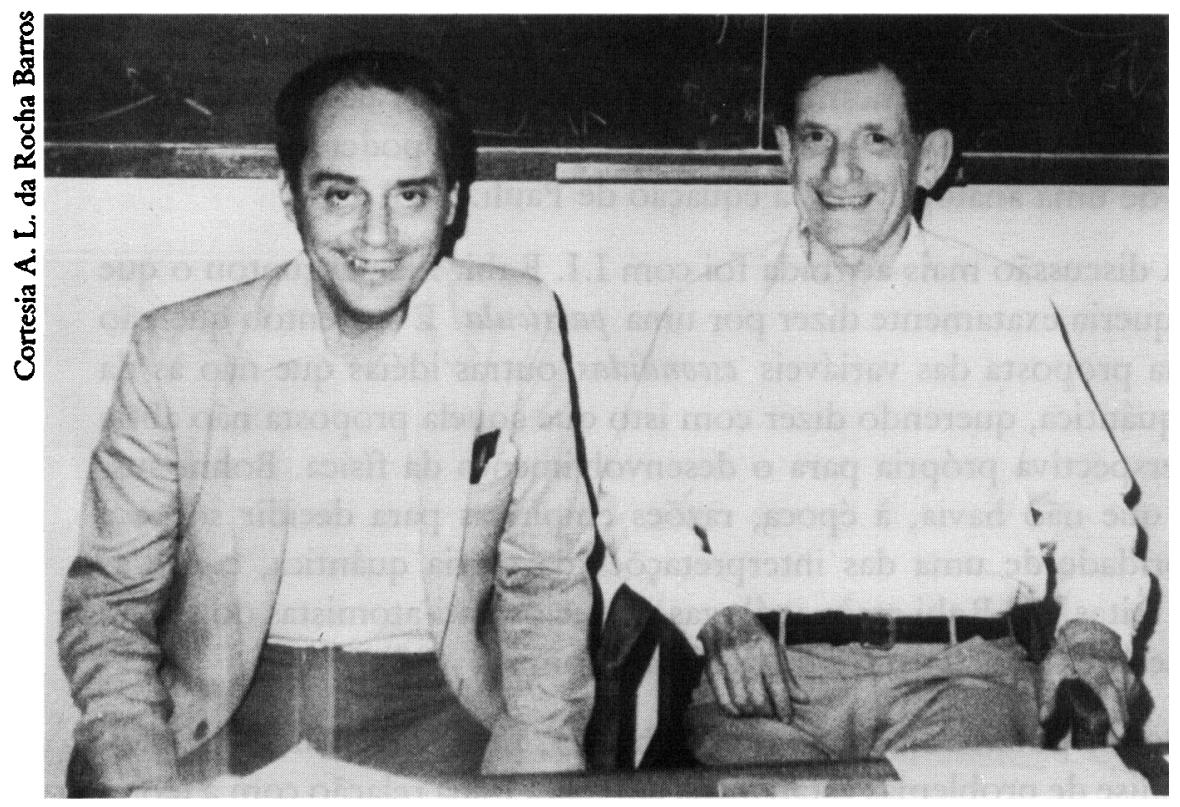

O professor $A . L$. da Rocba Barros (E) e David Bobrin no Birkbech College da Universidade de Londres, em 1983

cientifica, embora tenha sido cético quanto à sua eficácia para resolver os problema da mecdnica qudntica, mas isto provavelmente porque ela estava associada, na defesa de Popper a uma certa interpretação da teoria quântica - teoria estatística mas de base indeterminística - distante das posiçóes sustentadas por Bohm (85).

$\mathrm{Na}$ conclusão do trabalho Bohm-Schützer encontramos o seguinte agradecimento, indicativo de discussóes ocorridas quando de sua elaboração: "Nós desejamos agradecer ao Professor Mario Schönberg, ao Dr. Mario Bunge e a J.A. Meyer por muitas discussões estimulantes e instrutivas, as quais desempenharam um papel muito importante na clarificação de nossas idéias" (86). 
Ao longo do nosso estudo ficou ressaltado que a sociedade brasileira foi capaz de acolher o cientista e cidadáo perseguido politicamente, e assegurar a continuidade de seu trabalho científico, apesar de condiçóes nacionais - políticas, científicas e educacionais - adversas. A ciência brasileira muito se beneficiou do ensino, da pesquisa e da permanente preocupação com os fundamentos da física, características da obra de David Bohm.

\section{Notas}

1 O significado da estada de David Bohm no Brasil ainda não foi suficientemente avaliado. B.J. HILEY e F.D. PEAT no excelente livro que editaram, Quantum implications: essays in honour of David Bobm (London, Routledge \& Kegan Paul, 1987), falam resumidamente: "felizmente ele tinha alguns amigos no Brasil que foram capazes de oferecer-lhe uma posiçăo na Universidade de São Paulo, onde permaneceu de 1951 a 1955", na introdução, da permanência de Bohm no Brasil. O presente artigo procura aprofundar este significado. Mesmo que o leitor não compreenda bem algumas consideraçóes físico-teóricas, embora necessárias, certamente compreenderá o seu significado geral no contexto.

2 D. BOHM. A suggested interpretation of the quantum theory in terms of bidden variables, I and II - Physical Review, v.85, n.2, 1952, p.166-179 e 180-193.

3 Ver M. JAMMER. David Bohm and his work - on the occasion of his seventieth birthday, Foundations of Physics, v.18, n.7, 1988, p.691-699.

4 D. BOHM. Quantum theory. New York, Prentice Hall, 1951. Reimpresso pela DOVER, 1989.

5 A expressão McCarthysm não dá conta das restriçóes às liberdades políticas ocorridas nos Estados Unidos, nos governos Truman e Eisenhower, sob o pretexto da ameafa comunista. O Senador Joseph McCarthy foi um personagem menor neste contexto, conforme sustenta Argemiro Ferreira. Note-se que David Bohm foi chamado a depor em 1949 e o Senador McCarthy só entrou na campanha anti-comunista em 1950. Foi a propósito desta situaçăo, na qual cientistas foram incitados a denunciar seus colegas, que Einstein declarou que em situaçōes como esta preferiria ser encanador em vez de cientista. Da literatura, bastante diversificada, sobre o período registramos, em língua portuguesa, o livro de Argemiro Ferreira, Caça dis bruxas - macartismo: uma tragédia americana, Porto Alegre, L\&PM, 1989, que dispōe de razoável referência bibliográfica.

6 Conforme relato de Jessica Wang: Science, security, and the Cold War the case of E.U. Condon. ISIS, 83, 1992, p.238-289, especialmente p.257.

$7 \mathrm{~J}$. Wang sustenta que "cientistas fizeram dramáticas declaraçóes contra as políticas de segurança da Guerra Fria mas, como grupo, não estabeleceram políticas efetivas para defender cientistas individualment ou desafiar as 
premissas do estado de segurança nacional". Ver J. WANG, Science, security, and the Cold War, op.cit., p.240.

8 Carta de A. Einstein a A. de Moraes, 24.05.1952 e cartas de A. Einstein a Getúlio Vargas e Lucas Nogueira Garcez, 24.05.1952 (Aos cuidados de A. de Moraes), e também carta de A. de Moracs a A. Einstein, 12.05.1952. Fonte Archives Einstein.

9 Ainda neste contexto, da institucionalização da física brasileira, o Instituto Tecnológico da Aeronáutica (ITA) mobilizou professores como R. Feynman para cursos de atualização de professores de física. Entre os alunos estavam J. Israel Vargas e Beatriz Alvarenga, conforme comunicaçăo do Professor Darwin Bassi ao $X$ Simposio Nacional de Ensino de Física, Londrina, 1993.

10 Para referências deste período da institucionalização da pesquisa em física ver J. COSTA RIBEIRO, A física no Brasil. $n$ : F. de AZEVEDO, As ciências no Brasil, 2 v. Rio de Janeiro, Melhoramentos, 1955, v.I, p.163-202; S. MOTOYAMA, A física no Brasil. IN: M.G. FERRI e S. MOTOYAMA, Historia das ciências no Brasil, 3 v. São Paulo, EPU/EDUSP, 1979, v.I, p.61-91 e S. SCWARTZMAN, $A$ formafáo $d a$ comunidade cientifica no Brasil. Rio de Janeiro, Nacional, 1979, p.285-290.

11 D. BOHM. O aparente e o oculto. Entrevista a A.L. da Rocha Barros, Estudos Avanf̧ados, v.4, n.8, 1990, p.188-198. (Entrevista realizada em Londres, 8 mar. 1983). Esta entrevista foi publicada inicialmente em A.L. da ROCHA BARROS (ed), Perspectivas em física tebrica - Simpósio em Homenagem ao $70^{\circ}$ aniversário de Mário Schenberg. São Paulo, Instituto de Física e Coordenadoria Cultural da USP, 1987, p.47-61.

12 D. BOHM. Curso de fisica teórica, 2 v., redigidas por Paulo Saraiva Toledo, São Paulo, USP, 1952.

13 D.BOHM. Relatório de atividades da cadeira de Fisica Tebrica e Matemática 1951-1954, não publicado, microfilmado como parte do Processo 816/51 da Faculdade de Filosofia, Ciências e Letras da USP.

14 D. BOHM. Comparação entre a Física no Brasil e nos Estados Unidos, Notas de Matemática e Física, n.1, 1953, p.11-28.

15 A. EINSTEIN. Carta a D. Bohm, 25.01.1954, Ciência Hoje, V.15, n.90, 1993, p.44-47.

16 D. BOHM. Carta a A. Einstein, 3 fev. 1954. Para a integra da carta ver Ciência Hoje, v.15, n.90, 1993, p.44-47.

17 Por exemplo: Folba de S. Paulo, 11 jul. 1993, p.6-14 e O Estado de S. Paulo, 10 jul. 1993 , p.14.

18 Judith Lieblich Patarra reconstituindo o ambiente vivido em certos círculos judaicos, em São Paulo e neste período, observou que "em 1953, ano que as discussōes políticas estiveram muito presentes em casa de judeus - Julius e Ethel Rosenberg foram eletrocutados e morreu Stalin - ...". J.L. PATARRA. IARA, Rio de Janeiro, Rosa dos Tempos, 1992, 2a.ed, p.52. 
19 A. Ferreira, op.cit., p.102.

20 Ciencia Hoje, v.15, n.90, 1993, p.44-47.

21 A. EINSTEIN. Carta a N. Rosen, 11 mar. 1954.

22 Cf. Ficha de Cadastro na Faculdade de Filosofia, Letras e Ciências Humanas da USP.

23 Depoimento a A.L. da Rocha Barros. Estudos Avanfados, v.4, n.8, 1990, p.188-198.

24 Entrevista com O. Freire Jr., 25 jan. 1992.

25 D. BOHM. Quantum theory, op.cit.. O livro é uma exposiçāo nos marcos da interpretação usual da teoria ainda que com enfoque próprio ao abordar o problema da medida, um dos problemas mais sensiveis da interpretaçáo da teoria quântica. Mas não se limita à apresentação de resultados já estabelecidos, ele desenvolve, por exemplo, o experimento em pensamento EPR, (Gedankenexperiment, experiência que apenas pode ser imaginada), proposto em 1935 por Einstein, Podolsky e Rosen, para variáveis bivalentes como componentes de spin, conferindo assim grande simplicidade matemática à descriçāo teórica do fenômeno imaginado. Foi sob esta forma que Bell desenvolveu, em 1964, o que hoje denominamos desigualdades de Bell. Por isto alguns autores incluem o nome de Bohm no título do experimento. Ver A. ASPECT, P.GRANGIER \& G. ROGER, Experimental realization of Einstein-Podolsky-Rosen-Bohm Gedankenexperiment: a new violation of Bell's inequalities, Physical Review Letters, v.49, n.2, 1982, p.91-94,

26 Depoimento a A.L. da Rocha Barros, Estudos Avançados, v.4, n.8, 1990, p.188-198.

27 M. JAMMER. The philosopby of quantum mechanics - the interpretation of quantum mechanics in bistorical perspective. New York, John Wiley \& Sons, 1974, p.278-296.

28 D. BOHM. A suggested interpretation, op.cit.

29 Referência à cidade onde foi gestada, sede do Instituto de Física dirigido por Niels Bohr.

30 Pauli mostrou que o modelo proposto por de Broglie não descrevia adequadamente problemas de espalhamento de partículas lançadas contra um rotor, quando se considerava colisóes inelásticas. Ver Electrons et photons Conseil Solvay 1927, Paris, Gauthier-Villars, 1928, p.280-282.

31 Ele escreve o campo físico do modelo como $\Psi=\mathbf{R} \exp (\mathrm{i} \mathrm{S} / \hbar$ ), com $R$ e $S$ sendo funçóes reais. Substituindo esta função na equaçāo de Schrödinger ele obtém as equaçōes:

(1) $\partial \mathrm{P} / \partial \mathrm{t}+\operatorname{div}(\mathrm{P} \operatorname{grad} \mathrm{S} / \mathrm{m})=0$

(2) $\partial S / \partial t+(\operatorname{grad} S)^{2} / 2 \mathrm{~m}+\mathrm{V}-\hbar^{2} / 4 \mathrm{~m}\left(\nabla^{2} \mathrm{P} / \mathrm{P}-[\operatorname{grad} P)^{2} / 2 \mathrm{P}^{2}\right]=0$ $(\operatorname{grad} P) 2 / 2 \mathbf{P} 2)=0$, onde $\mathbf{P}=\mathbf{R}^{2}$. A proposta de Bohm de interpretar o último termo de (2) 
como um potencial quántico a ser incluído no Hamiltoniano, e a suposição do momento da partícula como grad.S, convertem a equação (2) na equação de Hamilton-Jacobi, de grande generalidade na mecânica clássica.

32 O momento da partícula, que é dado pelo gradiente de $S$, a validade da equação de Schrödinger e a equivalência entre a função $R 2$ do modelo e a densidade de probabilidade própria da teoria quântica.

33 Sobre a problemática da não-localidade substituindo a do determinismo, ver M. PATY, La non-séparabilité locale et l'objet de la théorie physique, Fundamenta Scientiae, 7, 1986, p.47-87.

34 S. BELL. On the problem of hidden variables in quantum mechanics. Review of Modern Physics, 38, 1966, p.447-452. Republicado em J.S. BELL, Speakable and unspeakable in quantum mechanics, Cambridge, Cambridge University Press, 1987, p.1-13 e traduzido por O. Pessoa Jr. em Cadernos de História e Filosofia da Ciência, série 3, v.2, n.2, 1992, p.243-257.

35 Ver, além das referências já incluídas neste artigo, J.L. DESTOUCHES. Retour sur le passé. In: A. GEORGE (ed), Louis de Broglie, physicien et penseur, Paris, Editions Albin Michel, 1953, p.67-85; S.T. EPSTEIN. The causal interpretation of quantum mechanics. Physical Review, v.89, 1952, p.319 e Physical Review, v.91, n.4, 1953, p.985.

36 Ver D. BOHM. Reply to a criticism of the causal re-interpretation of quantum theory. Physical Revicw, v.87, 1953, p.389-390; Comments on an article of Takabayasi concerning the formulation of quantum mechanics with classical pictures. Progress of Theoretical Physics, v.9, n.3, 1953, p.273-287; e Comments on a letter concerning the causal interpretation of the quantum theory, Physical Review, v.89, 1952, p.319-320; além das referências já contidas neste artigo.

37 A ausência de estudos históricos sobre este período da atividade de Bohm tem contribuído para afirmaçóes imprecisas como esta: "Histórias de cientistas como Frank Oppenheimer e David Bohm, que foram forçados a abandonar a pesquisa por anos, elevou a tensão entre cientistas" . J. WANG, op.cit., p.267.

38 Para uma análise mais abrangente das discussóes e correspondência entre Bohm e Einstein, das relaçōes e diferenças dos respectivos programas científicos, ver M. PATY, Sur les variables cachées de la mécanique quantique - Albert Einstein, David Bohm et Louis de Broglié, La Pensée, 292, 1993, p.93-116. Para uma análise da posição de Einstein face à teoria quântica, ver M. PATY, Einstein, les quanta et le réel, a aparecer.

39 A. EINSTEIN. Elementare Überlegungen zur Interpretation der Grundlagen der quanten-mechanik. In: Scientific papers presented to Max Born, Edinburgh, Oliver and Boyd, 1953, p.33-40. Existe uma tradução francesa recente: Réflexions élémentaires concernant l'interprétation des fondements de la mécanique quantique. In: A. EINSTEIN, Oeurres choisies, v.1 (Mécanique statistique et physique quantique), Paris, F. Balibar, B. Jech et O. Darrigol (eds.), 1989, p.251-256. 
40 A velocidade é dada pelo gradiente de $S / \mathrm{m}$, e para este fenómeno será nula pois a função $S$ não depende das coordenadas espaciais.

41 D. BOHM. A suggested interpretation, op.cit., p.193.

42 N. ROSEN. On waves and particles. Journal of the Mitchel Society, 61, 1945, p.67-73.

43 D. BOHM. A discussion of certains remarks by Einstein on Born's probability interpretation of the $\Psi$ function. In: Scientific papers presented to Max Born, Edinburgh, Oliver and Boyd, 1953, p.13-19.

44 Esta proximidade epistemológica entre D. Bohm e N. Bohr foi identificada por Jammer que, referindo-se à parte II do trabalho de Bohm, (1952) afirma: "... sua ênfase, provavelmente sob o impacto das críticas de Pauli, sobre a dependência das medidas de probabilidade das variáveis escondidas com referência ao tipo de observáveis medidos, isto é, sobre a relaçáo integral entre o sistema e o dispositivo de medida, é obviamente um definido rapprochement com a caracteristica de totalidade de Bohr". Ver M. JAMMER, The philosoply of quantum mechanics, op.cit., p.286-287. Ver também J. $\mathrm{BUB}$, Hidden variables and the Copenhagen interpretation - a reconciliation. Brit.J.Phil.Sci., 19, 1968, p.185-210, onde esta proximidade é analisada mais amplamente. $O$ próprio Bohm reconhecia, em algumas ocasiōes, esta proximidade. Em 1957, debatendo com L. Rosenfeld, que tinha posiçōes muito próximas das posiçóes de Bohr, ele declarou: "A diferença entre a minha posição e a do Prof. Rosenfeld é esta: ambos concordamos que a presente mecânica quântica implica que o aparelho desempenha um papel muito fundamental ajudando a produzir [o fenômeno], porque existe um acoplamento muito sensível entre o objeto e o aparelho. Mas eu proponho um modelo que visa explicar porque isto acontece". $S$. Körner, Observation and interpretation in the philosopby of physics - with special reference to quantum mechanics. New York, Dover Publications, 1957, p.61.

45 W. PAULI. Remarques sur le problème des paramètres cachés dans la mécanique quantique. In: A. GEORGE (ed), Louis de Broglie - physicien et penseur, op.cit., p.33-42.

46 J.B. KELLER. Bohm's interpretation of the quantum theory. In: Terms of Hidden variables. Physical Review, v.89, n.5, 1953, p.1040-1041.

47 O. HALPERN. A proposed re-interpretation of quantum mechanics. Physical Review, v.87, 1952, p.389; T.TAKABAYASI. On the formulation of quantum mechanics associated with classical pictures. Progress of Theoretical Physics, v.8, n.2, 1952, p.143-182; e Remarks on the formulation of quantum mechanics with classical pictures and on relations between linear scalar-fields and hydrodynamical fields. Progress of Theoretical Physics, v.9, n.3, 1953 , p.187-222.

48 H. FREISTADT. The crisis in physics. Science and Society, v.17, 1953, p.211-237 e E. SCHATZMAN. Physique quantique et realité. La Pensée, 42-43, 1952, p.107-122. 
49 L. ROSENFELD. L'évidence de la complementarité. In: L. de BROGLIE. Physicien et penseur, op.cit., p.43-65. As discussões entre Bohm e Rosenfeld tiveram seu ápice em um Simpósio, em 1957, em Bristol, quando após a exposição de cada um seguiu-se acirrado debate. Mas a critica de Rosenfeld nem sempre foi exclusivamente epistemológica. No debate citado, por exemplo, ele sustentou que "um esquema como o de Bohm não pode ser inteiramente consistente logicamente e compatível com a existência do quantum de açăo. Para as duas intervençóes e o relato dos debates, ver S. Korner (ed). Observation and interpretation, op.cit., p.31-61. Esta mesma critica foi feita por Niels Bohr, conforme relato do próprio David Bohm. Ver D. BOHM. Wholeness and the implicate order, London, ARK Paperbacks, 1983, p.84.

50 T. TAKABAYASI, op.cit.

51 Ao modelo desenvolvido por Bohm, que ele denomina de onda-piloto, de Broglie contrapóe o modelo da dupla-solução alterando a linearidade do formalismo da teoria quântica. Para uma revisão das suas posiçóes, ver L. de BROGLIE. La physique quantique restera-t-elle indéterministe? (1952). In: L. de BROGLIE. Nouvelles perspectives en microphysique, Paris, Albin Michel, 1956.

52 D. BOHM. Proof that probability density approaches $\Psi^{2}$. In: Causal interpretation of the quantum theory. Physical Review, v.89, n.2, 1953, p.458-466 (ver nota 4, à p.460). Uma versão reduzida, e simplificada, foi apresentada em Simpósio Internacional e está publicada em New research techniques in physics. Procecdings, [Rio de Janeiro and São Paulo, July, 15-29, 1952], Rio de Janeiro, 1954, p.187-198.

53 D. BOHM \& J.P. VIGIER. Model of the causal interpretation of quantum theory in terms of a fluid with irregular fluctuations. Physical Review, v.96, n.1, 1954, p.208-216.

54 D. BOHM. Proof that probability, op.cit.

55 J.P. Vigier, que tem prosseguido a pesquisa sobre modelos de variáveis escondidas, declarou recentemente: "a estada no Brasil, para mim, foi muito importante para responder algumas questōes fundamentais que David Bohm havia suposto à época". Entrevista com O. Freire Jr., 27 jan. 1992, a ser publicada. A colaboraçăo Vigier-Bohm estendeu-se a modelos de hidrodinâmica relativística.

56 D. BOHM, R. SCHILLER and J. TIOMNO. A causal interpretation of the Pauli equation (A). Nuovo Cimento, Suppl. ao v.I, n.1, 1955, p.48-66; e D. BOHM \& R. SCHILLER. A causal interpretation of the Pauli equation, (B). Nuovo Cimento, Suppl. v.I, n.1, 1955, p.67-91.

57 Ver D. BOHM. Hidden variables in the quantum theory. In: R. BATES. Quantum theory, v.III - Radiation and high energy physics. New York, Academic Press, 1962, 345-387, p.386. Reproduzido em D. BOHM. Wholeness and the implicate order. London, ARK, 1983; traduzido para o português por M. de Campos Silva e revisado por N.R. Eichenberg em D. BOHM, A totalidade e a ordem implicada, Sáo Paulo, Cultrix, 1992. 
58 Depoimento a O. Freire Jr. - abr. 1993.

59 D. BOHM. Hidden variables in the quantum theory, op.cit.

60 A apresentação destas idéias está em D. BOHM. Quantum theory as an indication of a new order in physics. Part A. The development of new orders as shown through the history of physics. Foundations of Pbysics, v.l, n.4, 1971, 359-381, p.362; e Part B, Implicate and explicate order in physical law. Foundations of Physics, v.3, n.2, 1973, p.139-168. Reimpressos em Wholeness and the implicate order, op.cit. Ver também a análise de R. LESTIENNE. Four ideas of David Bohm on the relationship between quantum mechanics and relativity. In: J.LEITE LOPES \& M. PATY (eds). Quantum mechanics, a balf century later, Reidel, Dordrecht, 1977, p.227-236.

61 D. BOHM. Quantum theory as an indication, op.cit., p.362.

62 Por exemplo, A. RIOJA. Orden implicado versus orden cartesiano. Reflexiones en torno a la filosofia de David Bohm, LLULL, 15, 1992, p.369-394. Ver também D. BOHM and F. DAVID PEAT. Science, order \& creativity, London, Routledge, 1989.

63 D. BOHM \& Y. AHARONOV. Significance of eletromagnetic potentials in the quantum theory. Physical Review, v.115, n.3, 1959, p.485-491.

64 D. BOHM \& Y. AHARONOV. Discussion of experimental proof for the paradox of Einstein, Rosen, Podolsky. Physical Review, v.108, n.4, 1957, p.1070-1076

65 Com esta compreensão um dos autores criticou a redução da obra de Bohm ao contexto dos anos 50. O. Freire Jr. Response to cross-comment on "The crisis in physics". Social Studies of Science, v.22, n.4, 1992, p.739-742.

66 D. BOHM. O aparente e o oculto, op.cit.

67 M. BUNGE. Hidden variables, separability, and realism. Revista Brasileira de Fisica, v. esp., jul. 1984, p.150-168.

$68 \mathrm{M}$. SCHENBERG. A non-linear generalization of the Schrödinger and Dirac equations, I e II. Nuovo Cimento, v.11, n.6, 1954, p.674-682; e 12, 1954, p.649.

69 M. SCHENBERG. Simple solution of the generalized Schrödinger equations. Nuovo Cimento, v.12, 1954, p.300; e Simple solutions of the generalized Schrödinger and Dirac equations. Nuovo Cimento, v.12, n.6, 1954, p.l.

$70 \mathrm{M}$. SCHENBERG. On the hydrodinamical model of the quantum mechanics. Nuovo Cimento, v.12, 1954, p.103; e Vortex motion of the madelung fluid. Nuovo Cimento, v.3, 1955, p.543.

71 Ver M. SCHENBERG, Quantum kinematics and geometry. Nuovo Cimento, Suppl. 6, 1957, p.356. Para uma noticia concisa sobre estes traba- 
lhos de Schenberg, ver A.L. da ROCHA BARROS. Schenberg e as álgebras geométricas da teoria quântica. Boletim Informativo da Sociedade Brasileira de Fisica, n.1, jun. 1991, p.7-9; e para diversos trabalhos relacionados à obra cientifica de Schenberg, ver A.L. da ROCHA BARROS (ed.), Perspectivas em fisica térica. Simpósio Internacional em Homenagem aos 70 anos de Mario Schenberg, São Paulo, Instituto de Física da USP, 1987.

72 D. BOHM. O aparente e o oculto, op.cit., p.197.

73 N.C. FERNANDES. Mário Schenberg e descoberta da supersimetria, Boletim Informativo da SBF, jun. 1991, p.3-6.

74 A.L. da ROCHA BARROS. Schenberg e as álgebras geométricas da teoria quântica Boletim Informativo da SBF, jun. 1991, p.7-9. Ver também A.L. da ROCHA BARROS. Schenberg e a visão algébrica da realidade física; e N.C. FERNANDES. As álgebras de Grassmann-Schoenberg e grande unificaçăo. In: A.L. da ROCHA BARROS (ed). Perspectivas em física teórica, op. cit., p.130-143 e 368-390.

75 D. BOHM and B.J. HILEY. Relativistic phase space arising out of the Dirac ágebra. In: A. van der Merwe (ed). Old and news questions in physics, cosmology, philosophy, and theoretical biology. New York, Plenum Press, 1983, p.67-76.

76 F.A.M. FRESCURA \& B. HILEY. The algebraization of quantum mechanics and the implicate order. Foundations of Physics, v.10, n.9-10, 1980, p.705-722. Em outro artigo, escrito como contribuiçāo aos 70 anos de Schenberg, os mesmos autores afirmaram: "Schenberg já havia investigado tal assunto e mostrado que as estruturas subjacentes a estas álgebras são extensóes das álgebras comutativas e anti-comutativas de Grassman, as quais têm as mesmas estruturas que as álgebras bosônicas e fermiônicas dos operadores de criação e aniquilação. F.A.M. FRESCURA \& B. HILEY. Algebras, quantum theory and pre-space Revista Brasileira de Fisica, v. esp. 70 anos de $M$. Schoenberg, 1984, p. 49-86.

77 D. BOHM. Proof that probability (...). Pbys Rev, op.cit.

78 L. ROSENFELD. Causalité statistique et ordre en physique et en biologie. Anais da Academia Brasileira de Ciencias, v.26, n.1, 1954, p.47-50. Reproduzido em L. ROSENFELD. Selected Papers, R.S. COHEN and J. STACHEL (Eds.), Reidel, Dordrecht, 1979, p.47-50.

79 L. ROSENFELD. Carta a Niels Bohr, 21 abr. 1954, Catalog of the Bohr scientific correspondance. In: Archives for the bistory of quantum physics.

80 L. ROSENFELD. A filosofia da física atômica. Ciência e Cultura, v.6, n.2, 1954, p.67-72.

81 R.P. FEYNMAN. The present situation in fundamental theoretical physics. Anais da Academia Brasileira de Ciências, v.26, n.1, 1954, p.51-59.

82 J. LEITE LOPES. Richard Feynamn in Brazil: personal recollections, QUIPU, v.7, n.3, 1990, p.383-397. 
83 D. BOHM. Proof that probability (...). In: Proceedings of New Research Techniques in Pbysics, (Rio de Janeiro and São Paulo, July, 15-29, 1952), Rio de Janciro, 1954, p.187-198.

84 D. BOHM and W. SCHÜTZER. The general statistical problem in physics and the theory of probability. Nuovo Cimento, Suppl. ao v.II, Série X, n.4, 1955, p.1004-1047.

85 Bohm participou do Simpósio realizado em 1957, em Bristol, onde o trabalho de Popper foi apresentado. Ele declarou, logo após a exposiçăo: "... penso que em alguns casos existem vantagens em falar sobre propensóes. (...) Neste sentido parece ser uma contribuiçăo distinguir entre propensão e freqüência relativa". Mas considerou que a dualidade onda - partícula $\epsilon$ tão difícil de ser tratada na interpretação da propensão quanto em qualquer outra. A familiaridade de Bohm com as questōes da interpretaçăo da probabilidade ficou evidente quando a sua intervenção sobre questốes bastante técnicas - correlação da propensão com a "escola axiomática" de Kolmogoroff - foi acolhida favoravelmente na intervençáo final de Popper. Para o trabalho de Popper e o debate que se seguiu ver K.R. POPPER. The propensity interpretation of the calculus of probability, and the quantum theory In: S. Korner. Observation and Interpretation, op.cit., p.65-70 e 78-89.

86 Meyer posteriormente saiu do Brasil vindo a assumir a direção do Laboratório da Física Nuclear de Altas Energias da Escola Politécnica de Paris.

\section{Resumo}

Quando o artigo Uma proposta de interpretafáo da teoria quantica em termos de paridpeis" escondidas", de autoria de David Bohm, foi publicado, ele estava no Brasil, na Universidade de São Paulo. Atingido pelo McCarthysm, Bohm perdeu sua posição na Universidade de Princeton e, por isto, veio para o Brasil, onde permaneceu de outubro de 1951 a janeiro de 1955. Analisamos sua atividade neste período, incluindo sua interpretaçăo da teoria quântica, e a recepçăo desta pela comunidade científica. Destacamos que, apesar das condiçóes adversas, a sociedade brasileira foi capaz de acolher o cidadáo e cientista perseguido politicamente, e assegurar a continuidade de seu trabalho científico. A ciência brasileira foi bastante beneficiada pelo ensino, pela pesquisa e pela permanente preocupaçāo com os fundamentos da física, características do trabalho de David Bohm.

\footnotetext{
Abstract

When the paper $A$ Suggested interpretation of the quantum theory in terms of " bidden" pariables, by David Bohm, was published he has been in Brazil at University of São Paulo. He was hit by the McCarthysm, lost his post at the Princeton University and by this he came to the Brazil, where he stayed from 1951 (October) to 1955 (January). We analysed his activity in this period, including his interpretation of the quantum theory and its reception in the scientific community. We pointed out that notwithstanding the adverse
} 
conditions, the Brazilian society was able to recept the political persecuted scientist and citizen and to warrant the continuity of his scientific work. The Brazilian science was very benefited by the teaching, the research and the permanent preoccupation with the foundations of physics, features of David Bohm's work.

Os autores agradecem à professora Amélia Hamburger, a leitura e observaçóes; à professora Suzana Barros, o depoimento; a Augusto Buonicore, as indicaçōes bibliográficas sobre o McCarthysm; a Pedro de Oliveira, a leitura; a Osvaldo Pessoa Jr., a leitura de uma versão preliminar intitulada Bobm a a teoria quantica; ao professor Henrique Fleming, a observação de que estada e estadia não têm o mesmo significado, significando a segunda "prazo concedido para carga e descarga do navio em um porto" (cf. Novo Dicionário Aurélio da Lingua Portuguesa, 2a. ed.); ao professor Tamás Szmrecsányi a sugestão, feita $\mathrm{em}$ reunião do conselho editorial de Estudos Avançados, de escrever um artigo sobre a estada de Bohm na USP. A responsabilidade exclusiva pelo texto é, naturalmente, dos autores. O. Freire Jr. agradece aos Archives for the History of Quantum Physics (Paris, La Vilette), pelas consultas. M. Paty agradece aos Archives Einstein o acesso às correspondências Einstein-Bohm. O. Freire Jr. foi parcialmente subsidiado pela Capes e CNPq.

Olival Freire Jr. é professor do Instituto de Física da Universidade Federal da Bahia, mestre em Ensino de Física pela USP e desenvolve atualmente pesquisa sobre história da física quântica.

Michel Paty é diretor de pesquisa do Centro Nacional de Pesquisa Científica (CNRS), da França e da Université Paris VII.

Alberto Luiz da Rocha Barros é professor do Instituto de Física da Universidade de São Paulo, trabalhou com David Bohm e Basil Hiley, sendo Researcher Fellow do Birbeck College da University of London, e integra a Mesa e o Conselho Editorial da revista Estudos Avançados. 